\title{
Development and validation of the critical thinking disposition inventory for Chinese medical college students (CTDI-M)
}

\author{
Xiaoxia Wang ${ }^{1} \mathbb{D}$, Xiaoxiao Sun², Tianhao Huang ${ }^{1}$, Renqiang He${ }^{1}$, Weina Hao ${ }^{1}$ and Li Zhang ${ }^{1 *}$
}

\begin{abstract}
Background: This study aimed to develop and conduct psychometric testing of the Critical Thinking Disposition Inventory to measure the critical thinking disposition of Chinese medical college students.

Methods: The study was conducted in two stages: (a) item generation, reliability analysis and exploratory factor analysis (EFA) and (b) confirmatory factor analysis (CFA) and testing of psychometric properties (Cronbach's alpha, test-retest reliability and convergent validity). The subjects included 1035 Chinese medical college students. The test-retest reliability of the instrument was determined at a two-week interval $(n=61)$. A general linear regression model was developed to examine the predictive effects of gender, age and major on CT disposition. The data were analysed with SPSS 22.0 and Amos 21.0 during item development and the reliability and validity analyses. Vista was utilized for parallel analysis during the principal axis analysis.
\end{abstract}

Results: Eighteen final items were sorted into 3 factors, which were identified as "Open-mindedness", "Systematicity/ Analyticity" and "Truth-seeking", with cumulative variance of 41.37, 46.00 and 49.59\%, respectively. The Cronbach's alpha was 0.924 , and the factors' alphas ranged from 0.824 to 0.862 . The correlational analysis indicated significant correlations between the subscales of the CTDI-CM and the total scores of the CTDI-CV, indicating modest evidence for the convergent validity of the CTDI-CM. Gender, age and education significantly predicted the CT disposition of Chinese medical students. Open-mindedness and Systematicity/Analyticity were higher for medical students than for nursing students.

Conclusions: This study presents a reliable and valid instrument for clinical thinking disposition. Future studies should explore other predictive factors of $\mathrm{CT}$ dispositions (e.g., cognitive/motivational) and criterion validity.

Keywords: Critical thinking disposition, Critical thinking disposition inventory for Chinese medical college students (CTDI-M), Medical college students, Validity, Reliability

\section{Background}

Critical thinking is increasingly needed to produce adaptive and flexible learners in the information age (Dwyer, Hogan, \& Stewart, 2014). The importance of being 'critical' for medical students and practitioners has also been increasingly emphasized [1]. The Delphi Report presented in 1990 by experts from the US and Canada defined critical thinking $(\mathrm{CT})$ as the ability to apply cognitive skills (interpretation, analysis, inference, evaluation, explanation,

\footnotetext{
*Correspondence: zhangli-372@163.com

'Department of Basic Psychology, School of Psychology, Army Medical University, Chongqing 400038, China

Full list of author information is available at the end of the article
}

and self-regulation) and the disposition towards CT (being open-minded or intellectually honest) [2, 3]. Critical thinking has frequently been referred to as individuals' cognitive ability to think and make correct decisions independently and to utilize rational/logical thought $[4,5]$.

Increasing attention has been paid to the individual differences in critical thinking disposition, which is defined as the tendency or attitude to utilize a particular skill voluntarily and the willingness to make the effort to apply it [6], or, simply put, the attitude towards critical thinking. Dispositions towards critical thinking are vital to critical-thinking performance [7] and professional clinical judgement [8]. Practically, both disposition and

(c) The Author(s). 2019 Open Access This article is distributed under the terms of the Creative Commons Attribution 4.0 International License (http://creativecommons.org/licenses/by/4.0/), which permits unrestricted use, distribution, and 
ability are necessary for critical thinking [9]. The assessment of CT dispositions may help to identify targets to promote critical thinking through training programmes in both professional and educational contexts.

The most widely used measurement tool in China for this purpose is the translated version of the California Critical Thinking Disposition Inventory (CCTDI) [10, 11]. The CCTDI is designed for the general adult working population at all levels and for students in grades 10 and above. The CCTDI includes seven subscales: "Inquisitiveness", "Systematicity", "Analyticity", "Truth-seeking", "Open-mindedness", "Self-confidence" and "Maturity" [12]. Yeh et al. translated the CCTDI into Chinese and administered it to a sample of nursing undergraduate students in Taiwan. Compared to the English CCTDI (alpha $=0.79)$, the overall alpha $(0.71)$ of the Chinese CCTDI was inferior, and the internal consistencies (Cronbach's $\alpha$ ) of three subscales were inadequate (Open-mindedness $=0.34$, Analyticity $=0.40$, and systematicity $=0.47)[11]$. In addition, the content validity of these three subscales was moderate (CVI $=0.50$ to 0.67) compared to the English CCTDI subscales $(\mathrm{CVI}=$ 0.82 to 1 ). Peng et al. developed a conceptually equivalent version of the CCTDI, the CTDI-CV (Critical Thinking Disposition Inventory-Chinese Version), which showed more satisfactory subscale alphas ranging from 0.54 to 0.77 and an overall alpha of 0.90 . The CVIs for the "Open-mindedness", "Analyticity" and "Systematicity" subscales were improved to $0.90-1$. However, the Cronbach's $\alpha$ (Chinese CCDTI $=0.46, C T D I-C V=0.57)$ and the CVI (Chinese CCDTI $=0.70$, CTDI-CV $=0.60$ ) of the "Maturity" subscale were lower for both the Chinese CCTDI and the CTDI-CV than for the English CCTDI (alpha $=.64, \mathrm{CVI}=.90)$ [10]. In another translated Chinese version of the CCTDI for university students, the Cronbach's $\alpha$ of the "Open-mindedness" (0.39), "Systematicity" (0.43) and "Maturity" (0.45) subscales were also not satisfactory [13]. The conceptualizations and measurement of CT dispositions in the Chinese-speaking population merit further exploration.

An important factor that may explain the diversity of the psychometric characteristics of versions of the CCTDI is cultural sensitivity. According to a literature review, Asian students tend to show less critical thinking dispositions compared with students from non-Asian countries [14-16].

(1). Analyticity and Systematicity are the cognitive components of CT dispositions that are culturally sensitive. "Analyticity" means the use of evidence and the anticipation of possible consequences to resolve problems. "Systematicity" means being organized, focused and diligent in resolving problems. In comparison with American university students, the percentage of students with lower than moderate levels of "Analyticity" and "Systematicity" is greater in the Chinese population [13]. Specifically, for Chinese medical undergraduates, the average score for "Systematicity" was at the lowest level of all subscales of CT dispositions [17]. The Systematicity of Chinese nursing students was at a moderate level [10]. A previous study suggested that Western cultures tend to be analytic, whereas traditional Chinese societies tend to be holistic and synthetic, which is manifested in language [18], thinking models of medicine [19] and preferences for dialectical proverbs and dialectical resolution of social contradictions [20]. Since the cognitive components of CT dispositions are crucial for effective critical thinking, cultural differences in thinking patterns need to be considered in the context of Chinese culture.

(2). "Inquisitiveness", "Truth-seeking" and "Openmindedness" are the motivation components of CT dispositions. CT ability is presumed to be significantly related to learning motivation [21]. First, Inquisitiveness refers to the inclination to be curious and eager to learn knowledge that may not be of immediate use. This may encourage learners to engage in deep and creative reasoning [22]. Second, the average score for Truth-seeking was at the lowest level of all subscales of CT dispositions among Chinese medical undergraduates [17]. The Truth-seeking of Chinese nursing students was at a moderate level [10]. Asian university students tended to learn for pragmatic purposes compared to American university students, who tend to possess an attitude that values truth [23]. While Open-mindedness and Truth-seeking have been deemed important in good critical thinkers, only Truth-seeking significantly predicts Chinese students' critical thinking performance, and their responses are more concerned with seeking solutions from authorities or preconceptions rather than seeking independent evidence or reasoning [24]. Third, in comparison with American university students, the proportion of students displaying a lower than moderate level of Openmindedness is greater in the Chinese population [13]. Open-minded people in Asian culture may be more inclined to accept contradictory propositions and avoid social conflicts. These cultural diversities may explain the low internal consistency of "Openmindedness" for the CCTDI in Chinese nursing students [11]. Therefore, the motivation components of CT dispositions should focus on these culturally sensitive traits and examine how these traits may influence medical performance. 
(3). "Self-confidence" and "Maturity" are the personality components of CT dispositions. The Self-confidence subscale measures individuals' confidence in their thinking and reasoning processes. Emotionally taxing situations, threats to self-identity (e.g., gender prejudice) or inappropriate priorities of values challenge the self-confidence of critical thinkers and impair their self-reflection ability [3]. Thus, Self-confidence is particularly important to CT dispositions. The Maturity scale assesses the disposition towards judicious decision-making and thus requires self-reflection, which develops gradually from adolescence to adulthood. Chinese students who exhibit a lower than moderate level of Maturity constitute a greater proportion compared with American university students [13]. More research is needed to develop specialized instruments for the Chinese context.

Empirically, critical thinking is valued both for nursing [25] and clinical expertise [4]. Critical thinking can improve diagnostic skills and reduce errors in management [4]. Critical thinking constitutes not only logical thinking ability but also problem-solving ability, which is content dependent [26]. For instance, CT enhances the capacity to transfer knowledge and skills obtained from the classroom to the clinical context [27]. As a result, CT skills have been emphasized by the Global Minimum Essential Requirements (GMER) as one of the seven student competence domains [28]. The competences contained in the GMER define the learning outcomes of medical graduates that are required for medical practice [29]. These domains have been assessed with an objective structured clinical examination (OSCE) that defined competence in critical thinking and research as the ability to generate and test hypotheses with scientific methods [30]. Although critical thinking competencies are generic abilities, CT behaviours may be more effectively learned or taught in specific discipline settings [31]. Therefore, knowledge about the individual differences of CT dispositions specific to the medical discipline could facilitate the teaching of critical thinking. In contrast to the two Chinese versions of the CCTDI that were directed at nursing students only, the current study also included medical students during the development of the CT disposition assessment tool.

An instrument for measuring critical thinking dispositions developed independently for Chinese medical students aims to (1) increase the content validity of specific factors of CT disposition (i.e., Open-mindedness, Analyticity, Systematicity and Maturity) and (2) identify those traits with greater cultural differences and evaluate the criterion validity of their measurement.

\section{Methods \\ Participants and procedures \\ Phase 1 development and factor analysis of the critical thinking disposition inventory for Chinese medical college students (CTDI-CM)}

(1). A total of 161 clinical medicine undergraduate students, 10 educational specialists and 10 psychological specialists were recruited. An openended questionnaire ("What are the aspects of critical thinking disposition for medical college students?") was completed. Ultimately, 177 surveys were deemed valid and analysed (male: $n=$ 157 , age $=22.03 \pm 7.84$; female: $n=20$, age $=$ $23.45 \pm 8.41$ ). A total of 264 preliminary items were obtained (Table 1). Based on the conceptual framework from the literature review and the results of the open-ended questionnaire, 97 items were extracted and entered into a half-openended questionnaire.

(2). A total of 199 undergraduate students (clinical medicine $=138$, nursing $=61$ ) and 20 educational $/$ psychological specialists were recruited. A 97item half-open-ended questionnaire resulting from the responses of the open-ended questionnaire as well as a complementary open-ended question ("Please list other dispositions not included in the questionnaire .") was completed. The participants were required to rate each item in terms of its relevance (yes/no) to the content of CT dispositions. Ultimately, 209 surveys were deemed valid and analysed (male: $n=99$, age $=23.26 \pm 9.72$; female: $n=110$, age $=$ $23.45 \pm 8.41)$. The items $(n=61)$ endorsed by more than $50 \%$ of respondents as reflecting the conceptualization of CT disposition were identified and entered into a closed-ended questionnaire (Table 1).

(3). A total of 431 undergraduate students (clinical medicine $=299$, preventive medicine $/$ medical laboratory science $=71$, nursing $=61$ ) and 20 educational/psychological specialists were recruited. A closed-ended 61-item questionnaire of CT dispositions was completed (Table 1). Participants were required to complete the questionnaire on a fivepoint Likert-type scale $(1=$ disagree strongly; $2=$ disagree somewhat; $3=$ neutral; 4 = agree somewhat; 5 = agree strongly). Ultimately, 442 surveys were deemed valid and analysed (male: $n=342$, age $=$ $21.35 \pm 5.41$; female: $n=100$; age $=24.08 \pm 8.61$ ). Among this sample, 61 participants (majoring in nursing) completed the scale at a two-week interval. An 18-item questionnaire resulted from exploratory factor analysis (EFA). 
Table 1 The (semi-)open-ended and closed-ended questionnaire of Critical Thinking Disposition for Chinese medical college students (CTDI-CM)

\begin{tabular}{|c|c|c|c|}
\hline \multicolumn{2}{|l|}{ CT dispositions } & \multicolumn{2}{|l|}{ CT dispositions } \\
\hline 质疑 & Question & 灵活性 & Are flexible \\
\hline 不盲从 & Do not blindly obey & 无偏见地识别问题 & Identify problems without prejudice \\
\hline 审慎思考 & Think carefully & 范畴 (逻辑)归类 & Category (logical) classification \\
\hline 自我意识 & Are self-conscious & 解读、澄清含义 & Interpret and clarify meaning \\
\hline 寻求问题 & Seek to solve problems & 铸而不舍的探求 & Pursue with perseverance \\
\hline 避免情绪推理 & Avoid emotional reasoning & 知识的整合 & Integrate knowledge \\
\hline 分析资料 & Analyse data & $\begin{array}{l}\text { 对一件事情给出更多 } \\
\text { 可选择的意义 }\end{array}$ & Attach multiple possible meanings to one thing \\
\hline 评估信息 & Evaluate information & 辨识问题 & Identify problems \\
\hline 辨析差异 & Discriminate differences & 在辩论中发现漏洞 & Find loopholes in the debate \\
\hline $\begin{array}{l}\text { 不轻易、简单地依靠感知 } \\
\text { 觉 }\end{array}$ & Do not easily and simply rely on perception & 擅长知识迁移 & Are good at knowledge transfer \\
\hline 擅长推理 & Are good at reasoning & $\begin{array}{l}\text { 好问、多问、深问的 } \\
\text { 思维品质 }\end{array}$ & Tend to ask many deep questions \\
\hline 有效解释 & Give effective interpretations & 合理判断 & Make reasonable judgments \\
\hline $\begin{array}{l}\text { (2)不使自己原有的认识阻 } \\
\text { 碍判断 }\end{array}$ & $\begin{array}{l}\text { Avoid allowing existing cognition to hinder } \\
\text { judgments }\end{array}$ & 逻辑思考 & Think logically \\
\hline $\begin{array}{l}\text { 在收集大量信息基础上做 } \\
\text { 出正确判断 }\end{array}$ & $\begin{array}{l}\text { Make correct judgments based on collecting a } \\
\text { large amount of information }\end{array}$ & 抵制毫无根据的想法 & Resist unfounded ideas \\
\hline 意识到自己的偏见 & Realize own prejudices & 运用知识来解决问题 & Use knowledge to solve problems \\
\hline 无偏见地作出判断 & Make judgments without prejudice & 形成有充分根据的判 & Form well-founded judgments \\
\hline 创造性 & Are creative & (3)寻求证据 & Seek evidence \\
\hline $\begin{array}{l}\text { 有意识进行评判的心理状 } \\
\text { 态 }\end{array}$ & Have a mental state of conscious judgment & (6)寻找真相 & Find the truth \\
\hline 愿意重新建构自己的观点 & Are willing to rebuild own views & 谋划策略 & Plan strategy \\
\hline 预测 & Are inclined to predict & $\begin{array}{l}\text { (9)能够抓住事情深层 } \\
\text { 次问题 }\end{array}$ & Engage in in-depth thinking \\
\hline 有目的的自我调整 & Purposefully self-adjust & 确定某物的真实价值 & Determine the true value of something \\
\hline 理性地综合考虑各种情况 & Rationally consider various situations & (5)寻求多样性答案 & Seek solutions from many aspects \\
\hline 做出合理决定 & Make a reasonable decision & 认知监控 & Employ cognitive monitoring \\
\hline (1)公正客观对待事物 & Have a fair and objective attitude & 思维开放 & Have an open mind \\
\hline $\begin{array}{l}\text { 重视理由和证据在解决问 } \\
\text { 题中的作用 }\end{array}$ & $\begin{array}{l}\text { Emphasize the role of reason and evidence in } \\
\text { solving problems }\end{array}$ & $\begin{array}{l}\text { 从不同角度、不同方 } \\
\text { 向思考 }\end{array}$ & Think from different aspects and directions \\
\hline (4)接纳不同观点 & Accept different views & 自我修正 & Are capable of self-correction \\
\hline 对别人的意见敏感 & Sensitive to other people's opinions & 反思 & Engage in reflective thinking \\
\hline (7)明智和谨慎地做决定 & Make decisions wisely and prudently & 自我调节 & Are capable of self-regulation \\
\hline $\begin{array}{l}\text { (10)能动地、全面地分析 } \\
\text { 事物的各个方面 }\end{array}$ & Actively comprehensively analyse problems & 合适的推论 & Make appropriate inferences \\
\hline (13)主动思考 & Are active thinkers & $\begin{array}{l}\text { 阐明解决问题的多种 } \\
\text { 选择 }\end{array}$ & Clarify multiple options for solving problems \\
\hline (16)不迷信权威 & Do not have blind faith in authority & $\begin{array}{l}\text { 清晰、正确、精确陈 } \\
\text { 述 }\end{array}$ & Make clear, correct, accurate statements \\
\hline 独立意识 & Are capable of independent consciousness & $\begin{array}{l}\text { (8)不陷于惯性思维定 } \\
\text { 式 }\end{array}$ & Avoid the negative effects of mental set \\
\hline 敏锐的洞察力 & Are capable of keen insight & $\begin{array}{l}\text { 从多种角度考察合理 } \\
\text { 性 }\end{array}$ & Assess rationality from multiple directions \\
\hline 有效地理解知识 & Comprehend knowledge effectively & $\begin{array}{l}\text { 避免过失、错误或失 } \\
\text { 真 }\end{array}$ & Avoid mistakes, errors or distortions \\
\hline
\end{tabular}


Table 1 The (semi-)open-ended and closed-ended questionnaire of Critical Thinking Disposition for Chinese medical college students (CTDI-CM) (Continued)

\begin{tabular}{|c|c|c|c|}
\hline \multicolumn{2}{|l|}{ CT dispositions } & \multicolumn{2}{|l|}{ CT dispositions } \\
\hline 质疑 & Question & 灵活性 & Are flexible \\
\hline 谨慎地从证据中得出结论 & Carefully draw conclusions from evidence & $\begin{array}{l}\text { 现在思考与先前早已 } \\
\text { 思考的相一致 }\end{array}$ & Employ self-consistent thinking \\
\hline 认知成熟 & Cognitive maturity & $\begin{array}{l}\text { 陈述与当下的内容相 } \\
\text { 关联 }\end{array}$ & Make pertinent statements \\
\hline 有效地运用知识和经验 & Effectively use knowledge and experience & (12)逻辑思维 & Are capable of logical thinking \\
\hline 注意对研究证据的选择性 & $\begin{array}{l}\text { Identify selective interpretations of research } \\
\text { evidence }\end{array}$ & $\begin{array}{l}\text { 深入追溯问题, 全盘把 } \\
\text { 握各个方面 }\end{array}$ & Investigate issues thoroughly and fully \\
\hline 智力解决问题 & Are capable of intellectual problem solving & $\begin{array}{l}\text { (16)在表面理由背后 } \\
\text { 挖掘真相 }\end{array}$ & Distinguish truth from falsehood \\
\hline 智力确定行动方针 & Intellectually determine a course of action & (17)多方面审视问题 & View the problem in many ways \\
\hline 明智决断 & Make rational decisions & $\begin{array}{l}\text { 避免自我中心倾向思 } \\
\text { 维 }\end{array}$ & Avoid self-centred thinking \\
\hline 寻求信息 & Search information & (18)去伪存真 & Winnow truth from falsehood \\
\hline 处理信息的技巧 & Are skilled in information processing & $\begin{array}{l}\text { 有组织, 有目标地去努 } \\
\text { 力处理问题 }\end{array}$ & $\begin{array}{l}\text { Address problems with organization and } \\
\text { purpose }\end{array}$ \\
\hline 正确取舍 & Make the correct choice & (11)打破思维习惯 & Break habitual thinking patterns \\
\hline $\begin{array}{l}\text { 持慎思的怀疑态度去从事 } \\
\text { 活动 }\end{array}$ & $\begin{array}{l}\text { Are cautious and sceptical about engaging in } \\
\text { activities }\end{array}$ & $\begin{array}{l}\text { (15)不受偶然的暗示 } \\
\text { 而犹豫动摇 }\end{array}$ & $\begin{array}{l}\text { Do not allow unrealistic suggestions to } \\
\text { alter thinking }\end{array}$ \\
\hline $\begin{array}{l}\text { 持之以恒的、细心的、积 } \\
\text { 极的思考 }\end{array}$ & Persevere, with careful and positive thinking & $\begin{array}{l}\text { 真伪对错的剖析和评 } \\
\text { 断 }\end{array}$ & Analyse and judge truth/falsehood \\
\hline 合理思考 & Are capable of reasonable thinking & $\begin{array}{l}\text { 思维中遵循规律和标 } \\
\text { 准 }\end{array}$ & Follow the rules and standards in thinking \\
\hline 思维活跃 & Have an active mind & $\begin{array}{l}\text { 对自己的理性分析能 } \\
\text { 力有把握 }\end{array}$ & $\begin{array}{l}\text { Have confidence in their ability to analyse } \\
\text { rationally }\end{array}$ \\
\hline 辨析问题 & Discriminate and analyse the problem & 其他_ & $\begin{array}{l}\text { Please list other dispositions not included in the } \\
\text { questionnaire }\end{array}$ \\
\hline
\end{tabular}

Note: The items in italics represent the semi-open-ended questionnaire of CTDI-CM (61 items). The items in bold represent the final version of CTDI-CM (18 items)

\section{Phase 2 confirmation of factor structure of the CTDI-CM}

Confirmatory factor analysis (CFA) An independent sample of 441 undergraduate students and 641 medical graduate students (age $=26.73 \pm 3.96$ ) (enrolled in 2012) was recruited. The aims of the phase 2 data collection were (1) to confirm the factor structure of the 18-item CT disposition scale for Chinese medical students (CTDI-CM) and (2) to examine the generalization capacity of the CTDI-CM. Participants were required to complete the questionnaire on a five-point Likert-type scale ( 1 =disagree strongly; $2=$ disagree somewhat; 3 =neutral; 4 =agree somewhat; $5=$ agree strongly). A total of 420 surveys were deemed valid for undergraduate students (clinical medicine $=278$, preventive medicine $/$ medical laboratory science $=81$, nursing $=61$ ) (male: $n=323$, age $=$ $20.50 \pm 1.08$; female: $n=97$, age $=21.17 \pm 1.43$ ), and 641 surveys were deemed valid for graduate students (major not recorded during data collection due to technical problem) (male: $n=397$, age $=27.09 \pm 3.94$; female: $n=244$, age $=26.16 \pm 3.95)$.
Convergent validity A total of 289 medical undergraduate students (enrolled in 2014) (age $=19.57 \pm 1.63$ ) were recruited (male: $n=264$, age $=19.63 \pm 1.67$; female: $n=$ 23 , age $=18.87 \pm 0.81)$. Three versions of the CT disposition scales (CTDI-CM, CTDI-CV, CCTDI) were completed to estimate the convergent validity of the CTDI-CM. Only comparisons between the CTDI-CM and the CTDI-CV were reported due to the lack of a scoring system for the CCTDI.

The current study was approved by the ethics committee of the university. The data collection in each phase was conducted after the enrolment of each student (from April to June) and before the school year began (Fig. 1). This was intended to alleviate the learning effects of college course studies and academic training on CT disposition. Verbal informed consent was obtained from each participant prior to the surveys. All of the participants' information was confidential, and the participants could withdraw from the study at any time on a voluntary basis. The sample size had sufficient power to detect significant differences revealed by the power analysis. 


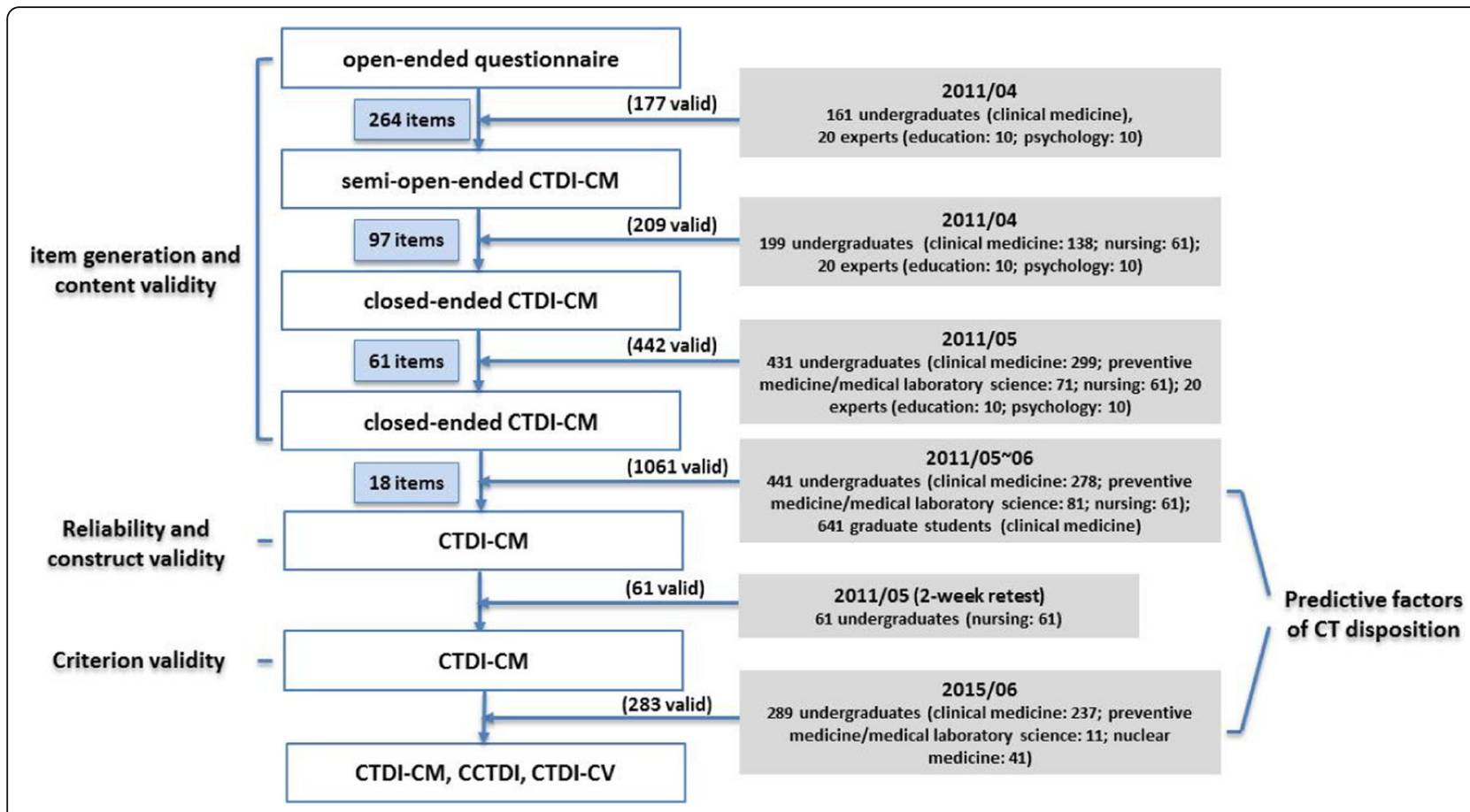

Fig. 1 Development of CTDI-CM and reliability/validity steps

\section{Statistics}

Statistical analysis was conducted using the Statistical Package for the Social Sciences (SPSS) 22.0 for Windows (SPSS, Chicago, IL, USA).

\section{Development of CTDI-CM and item analysis}

The remaining 18 items (Table 1) survived the two criteria of item analysis. (1) Item discriminability. A critical ratio (CR) index was used to quantify the difference of each item for the $27 \%$ highest-scoring group versus the $27 \%$ lowest-scoring group. Two independent-sample $t$ tests with a $C R$ value exceeding 3 indicated good item discriminability [32]. (2) Item homogeneity test. Item-total statistics were computed to examine the content homogeneity between items, with a value over 0.3 indicating that the item correlated well with the total scale [33].

\section{Reliability analysis of the CTDI-CM}

(1) For internal consistency, Cronbach's alpha coefficient was calculated for the scores of each subscale and the total scale based on the assumption that the CTDI-CM measures the single trait of CT disposition. The questionnaire had substantial internal consistency according to the following rules of thumb: $>0.9$ as excellent, $>0.8$ as good, $>0.7$ as acceptable, $>0.6$ as questionable, $>0.5$ as poor and $<0.5$ as unacceptable [34]. (2) Item-to-total correlations were examined with the recommended value of up to 0.3 [35]. (3) Test-retest reliability was analysed by the intra-class correlation coefficients (ICCs) with a two-week interval, which was long enough to avoid confounding effects of practice and allow for a natural change in the construct. ICC provides an estimate of the reproducibility (stability) of the assessments according to the following criteria: $>0.6$ indicates good reliability and $>0.74$ indicates excellent reliability [36].

\section{Validity analysis of the CTDI-CM}

Exploratory factor analysis (EFA) Principal axis factor analysis was performed to identify the latent variables of CT dispositions. The Kaiser-Meyer-Olkin (KMO) measure and Bartlett's Test of Sphericity were examined for the adequacy of the factor analysis. Factors were extracted based on Kaiser's (1960) eigenvalues-greater-than-1 rule and the scree test after a direct oblimin rotation solution. The validation procedures were implemented with SPSS 22.0. To replicate these results, we also conducted parallel analysis, which is recommended as a statistically based and more validated procedure for determining the number of components [37]. The parallel analysis was conducted with ViSta (visual statistics system) (https://www.uv.es/ visualstats/Book/DownloadBook.html) [38]. Parallel analysis using Monte Carlo simulations of permutations of 1000 randomly generated datasets was conducted. The eigenvalue of the raw data exceeding the eigenvalue of the 95th percentile (and mean) of random data could be extracted as a factor [37]. 
Confirmatory factor analysis (CFA) CFA analyses were performed using IBM SPSS Amos 21.0. CMIN/DF( $\approx 2)$, GFI (goodness-of-fit index) $\geq 0.90$, AGFI (adjusted goodness-of-fit index) $\geq 0.80$, CFI (comparative fit index) $\geq 0.90$ and $0.05 \leq$ RMSEA (root-mean-square error of approximation) $\leq 0.08$ are typically considered to indicate goodness of the model fit [39].

Convergent validity The intercorrelations among the scores of the subscales of the CTDI-CV and the CTDI-CM were computed. Pearson's correlation coefficient was estimated, with a significance level of $p<0.05$ for statistical testing. Pearson's $\mathrm{r}$ with a positive value greater than 0.70 is recommended (Terwee et al., 2007). To replicate the results, we also performed regression analyses for convergent validity with the CTDI-CM subscales as the predictors and the CTDI-CV total score as the outcome variable, with a positive beta coefficient of $0.40-0.59$ as recommended [40].

\section{GLM analysis of CT dispositions of Chinese medical college students}

The general linear regression model (model 1) was utilized to estimate the significant predictive factor of CT dispositions, with gender ( male $=1$; female $=2$ ), age and education (undergraduate student $=1$; graduate student $=2$ ) as independent variables and the subscale scores of the CTDI-CM (Open-mindedness, Systematicity/Analyticity, Truth-seeking) as dependent variables. The information on major for graduate students was omitted during the data collection. Thus, we only report the comparison between the two majors (medical vs. nursing) in undergraduate students.

\section{Results}

Item and reliability analysis

We obtained an 18-item questionnaire on Chinese medical college students' critical thinking dispositions. Item analyses showed that the items of the CTDI-M were recognized by the respondents as relevant to $\mathrm{CT}$ disposition. Additionally, these items could discriminate those with higher versus lower levels of CT disposition (Fig. 2) (Ps $<0.003$, Bonferroni corrected).

The item-total analysis confirmed the homogeneity of content among items (Table 2). The results also showed that the questionnaire had excellent internal consistency (0.776 0.965) and two-week test-retest reliability of the CDTI-CM (0.808 0.965) (Table 3).

\section{Validity analysis}

The Kaiser-Meyer-Olkin (KMO) measure of sampling adequacy was 0.946, which was greater than 0.5 (and close to one), indicating satisfactory factor analysis. Bartlett's Test of Sphericity $\left(X^{2}=3410.42, P<0.001\right)$ (less than 0.05) suggested the appropriateness of the factor analysis model. The principal axis factor analysis identified a three-factor model, with the eigenvalues of $3 \mathrm{fac}$ tors exceeding one (Table 4). The scree test confirmed the three-factor model of CT dispositions (Fig. 3). The first factor (Open-mindedness) explained $41.37 \%$ of the accumulated variance with seven items (with an eigenvalue of 7.95), which indicated an open attitude and willingness to listen to and consider other people's ideas and suggestions before arriving at conclusions. The second factor (Systematicity/Analyticity) explained $46.00 \%$ of the accumulated variance with six items (with an eigenvalue of 1.32), which indicated the traits of being painstaking and careful and demonstrating effective decision-making and problem-solving. The third factor (Truth-seeking) explained $49.59 \%$ of the accumulated variance with five items (with an eigenvalue of 1.12), which indicated the state of active curiosity, active engagement in thinking, and avoiding the negative effects of mental state. To replicate these results, three factors were extracted through parallel analysis after comparison of the actual data eigenvalues with the eigenvalues

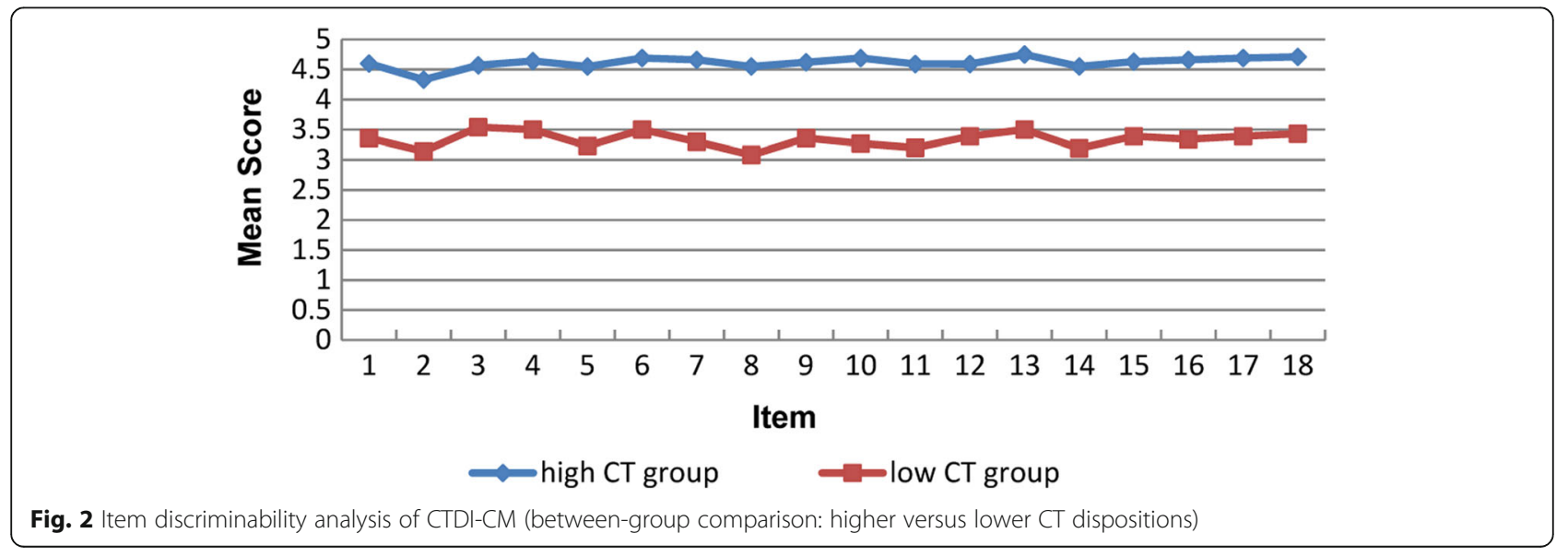


Table 2 Item-Total Statistics of CTDI-CM

\begin{tabular}{lllll}
\hline Item & $\begin{array}{l}\text { Scale Mean if } \\
\text { Item Deleted }\end{array}$ & $\begin{array}{l}\text { Scale Variance } \\
\text { if Item } \\
\text { Deleted }\end{array}$ & $\begin{array}{l}\text { Corrected Item- } \\
\text { Total } \\
\text { Correlation }\end{array}$ & $\begin{array}{l}\text { Cronbach's } \\
\text { Alpha if Item } \\
\text { Deleted }\end{array}$ \\
\hline 1 & 67.44 & 80.77 & 0.60 & 0.92 \\
2 & 67.71 & 81.54 & 0.53 & 0.92 \\
3 & 67.38 & 82.58 & 0.58 & 0.92 \\
4 & 67.37 & 81.61 & 0.55 & 0.92 \\
5 & 67.55 & 80.73 & 0.59 & 0.92 \\
6 & 67.36 & 81.44 & 0.64 & 0.92 \\
7 & 67.48 & 80.32 & 0.66 & 0.92 \\
8 & 67.63 & 80.24 & 0.60 & 0.92 \\
9 & 67.48 & 81.00 & 0.63 & 0.92 \\
10 & 67.45 & 79.78 & 0.69 & 0.92 \\
11 & 67.57 & 80.14 & 0.63 & 0.92 \\
12 & 67.43 & 81.40 & 0.62 & 0.92 \\
13 & 67.36 & 80.86 & 0.61 & 0.92 \\
14 & 67.62 & 79.76 & 0.62 & 0.92 \\
15 & 67.46 & 81.23 & 0.61 & 0.92 \\
16 & 67.38 & 81.00 & 0.53 & 0.92 \\
17 & 67.44 & 81.07 & 0.64 & 0.92 \\
18 & 67.37 & 80.36 & 0.69 & 0.92 \\
\hline & & & &
\end{tabular}

extracted from random data (Fig. 4). Additionally, CFA indicated the goodness of the three-factor model fit: CMIN/DF (2.103), GFI $(0.930 \geq 0.90)$, CFI $(0.956 \geq 0.90)$, AGFI $(0.909 \geq 0.80)$ and RMSEA $(0.05 \leq 0.051 \leq 0.08)$.

The convergent validity was examined by correlating the subscales of the CTDI-CM with the CTDI-CV. Open-mindedness on the CTDI-CM was positively correlated with Maturity and Self-confidence on the CTDI-CV $(r=0.170$, $P<0.005, n=282)$. The Systematicity/Analyticity of the CTDI-CM was positively correlated with self-confidence $(\mathrm{r}=$ $0.215, P<0.001, \mathrm{n}=282$ ) on the CTDI-CV and negatively correlated with Inquisitiveness on the CTDI-CV $(r=-0.219$, $P<0.001, n=284)$. Truth-seeking on the CTDI-CM was positively correlated with self-confidence on the CTDI-CV $(\mathrm{r}=0.200, P<0.005, n=280)$ and negatively correlated with Inquisitiveness $(\mathrm{r}=-0.318, P<0.001)$ and Analyticity $(\mathrm{r}=-$ $0.129, P<0.05, n=179)$ on the CTDI-CV. However, there was no significant correlation between the total scores of the CTDI-CV and the CTDI-CM $(r=0.028, P=0.643)$ (Table 5).
The VIF (2.237, 3.755 and 3.630) and tolerance scores ( 0.447 , 0.266 and 0.275 ) indicated no multicollinearity among the predictors.

\section{The predictors of $\mathrm{CT}$ dispositions: gender, age, education and major}

The multivariate general linear model (GLM) (model 1) indicated that education significantly predicted three CT dispositions (Open-mindedness, Systematicity/Analyticity, and Truth-seeking $)\left(P<0.001\right.$, partial $\eta^{2}=0.023$, $0.033,0.034)$ (Table 6). Similarly, age $(P<0.001$, partial $\left.\eta^{2}=0.021,0.014,0.013\right)$ and gender $(P<0.001$, partial $\left.\eta^{2}=0.014,0.013,0.012\right)$ significantly predicted the CT dispositions of medical students. Furthermore, an independent-sample t-test between medical and nursing students revealed that the mean scores for Open-mindedness and Systematicity/Analyticity were higher for medical students than for nursing students (Table 7).

\section{Discussion}

This study provided a preliminary instrument to measure the critical thinking dispositions of Chinese medical college students and presented its psychometric properties. The critical thinking dispositions of Chinese medical college students include Open-mindedness, Systematicity/Analyticity and Truth-seeking. Open-mindedness targets the openness to different viewpoints and possibilities before making a decision. Systematicity/Analyticity involves values such as fairness and truth and the skills to strive for sound and unbiased judgements. Truth-seeking refers to the enthusiasm for true knowledge and active engagement in thinking. The present study revealed that the Chinese version of the CDTI-CM for medical college students showed acceptable psychometric properties.

\section{Comparison among different versions of inventories for critical thinking dispositions}

Since non-cognitive factors may have a great impact on participants' critical thinking, such as culture and motivation [41], we compared the psychometric properties of the CTDI-CM with the Chinese CCTDI (California Critical Thinking Dispositions Inventory) [11] and the CTDI-CV (Critical Thinking Disposition Inventory-Chinese Version) [10], which were developed to be

Table 3 Reliability analysis of CTDI-CM

\begin{tabular}{lllll}
\hline Reliability & coefficient & & & \\
\cline { 2 - 5 } & total scale & Open-mindedness (Factor 1) & Systematicity/analyticity (Factor 2) & Truth seeking (Factor 3) \\
\hline Internal consistency reliability $(n=420)$ & $0.92^{*}$ & $0.86^{*}$ & $0.85^{*}$ & $0.824^{*}$ \\
Split-half reliability $(n=420)$ & $0.92^{*}$ & $0.81^{*}$ & $0.83^{*}$ & $0.776^{*}$ \\
Two-week test-retest reliability $(n=61)$ & $0.88^{*}$ & $0.81^{*}$ & $0.97^{*}$ & $0.907^{*}$ \\
\hline
\end{tabular}

${ }^{* *} p<0.01$ (2-tailed), Pearson correlation 
Table 4 Factor Loadings of Each Item of CTDI-CM (Critical Thinking Disposition Inventory for Chinese medical students)

\begin{tabular}{|c|c|c|c|c|c|c|}
\hline \multirow[t]{2}{*}{$\begin{array}{l}\text { Measurement } \\
\text { indicators (Factors) }\end{array}$} & \multirow[t]{2}{*}{ Items } & \multicolumn{2}{|c|}{$\begin{array}{l}\text { Rotated sums of squared } \\
\text { loadings }\end{array}$} & \multicolumn{3}{|c|}{$\begin{array}{l}\text { Rotated component } \\
\text { matrix(a) }\end{array}$} \\
\hline & & $\begin{array}{l}\% \text { of } \\
\text { variance }\end{array}$ & Cumulative \% & $\begin{array}{l}\text { Factor } \\
1\end{array}$ & $\begin{array}{l}\text { Factor } \\
2\end{array}$ & $\begin{array}{l}\text { Factor } \\
3\end{array}$ \\
\hline \multirow[t]{7}{*}{ Open-mindedness } & 8. Make decisions wisely and prudently (明智和谨慎地做决定) & $41.37 \%$ & $41.37 \%$ & 0.74 & 0.50 & -0.55 \\
\hline & 5. Accept different views (接纳不同观点) & & & 0.72 & 0.36 & -0.43 \\
\hline & 2. Have a fair and objective attitude (公正客观对待事物) & & & 0.71 & 0.45 & -0.48 \\
\hline & 19. Winnow truth from falsehood (去伪存真) & & & 0.71 & 0.51 & -0.64 \\
\hline & $\begin{array}{l}\text { 11. Actively comprehensively analyse problems (能动、全面分析事物的 } \\
\text { 各方面) }\end{array}$ & & & 0.71 & 0.59 & -0.56 \\
\hline & 14. Are active thinkers (主动思考) & & & 0.65 & 0.47 & -0.54 \\
\hline & 17. Do not have blind faith in authority (不迷信权威) & & & 0.55 & 0.41 & -0.46 \\
\hline \multirow[t]{5}{*}{ Truth seeking } & 9. Avoid the negative effects of mental set (不陷于惯性思维定式) & $4.63 \%$ & $46.00 \%$ & 0.45 & 0.78 & -0.46 \\
\hline & 12. Break habitual thinking patterns (打破思维习惯) & & & 0.49 & 0.76 & -0.51 \\
\hline & $\begin{array}{l}\text { 15. Do not allow unrealistic suggestions to alter thinking (不受偶然的暗 } \\
\text { 示而犹豫动摇) }\end{array}$ & & & 0.50 & 0.69 & -0.51 \\
\hline & $\begin{array}{l}\text { 3. Avoid allowing existing cognition to hinder judgments (不使原有认识 } \\
\text { 阻碍判断) }\end{array}$ & & & 0.42 & 0.63 & -0.41 \\
\hline & 6. Seek solutions from many aspects (寻求多样性答案) & & & 0.48 & 0.59 & -0.55 \\
\hline \multirow{6}{*}{$\begin{array}{l}\text { Systematicity/ } \\
\text { analyticity }\end{array}$} & 7. Find the truth (寻找真相) & $3.59 \%$ & $49.59 \%$ & 0.52 & 0.47 & -0.79 \\
\hline & 4. Seek evidence (寻求证据) & & & 0.52 & 0.38 & -0.71 \\
\hline & 16. Distinguish truth from falsehood (在表面理由背后挖掘真相) & & & 0.54 & 0.55 & -0.67 \\
\hline & 13. Are capable of logical thinking (逻辑思维) & & & 0.51 & 0.52 & -0.67 \\
\hline & 18. View the problem in many ways (多方面审视问题) & & & 0.51 & 0.50 & -0.66 \\
\hline & 10. Engage in in-depth thinking (能够抓住事情深层次问题) & & & 0.48 & 0.59 & -0.65 \\
\hline
\end{tabular}

conceptually or semantically equivalent to the original CCTDI, respectively. While the Chinese CCTDI verified construct validity for the Truth-seeking, Open-mindedness, Systematicity and Maturity subscales [11], the content validity (alpha $=0.34$ ) of Open-mindedness for the Chinese CCTDI was less satisfactory than the current study (alpha $=0.86$ ). Additionally, the criterion validity analysis revealed that Open-mindedness on the CTDI-CV was irrelevant to the three factors of the CTDI-CM. Thus, the content validity of the CTDI-CM is different from that of the CTDI-CV. Open-mindedness (CTDI-CM) means being open to divergent views and prudent in decision making and, most importantly, not being submissive to authority. By contrast, Open-mindedness (CTDI-CV) addresses the tolerance of divergent world views/cultures and readiness to monitor one's own cognitive bias. The attitude towards authorities may differentiate the content of the two measurements. Indirect evidence showed that Chinese undergraduate nursing students are not as open-minded as their American student counterparts [42] and have ambivalent attitudes towards this disposition [43]. Chinese students, as obedient learners, may be more submissive to their teachers and dependent on rules, which may hinder their willingness to be open-minded [44]. Consequently, the inclination towards open-mindedness may lead to more solid decision-related reasoning and prevent nurses from making medical errors when they implement doctors' clinical decisions. Therefore, the content of the Open-mindedness factor of the CTDI-CM may be more suitable to detect the potential inclination of these individuals.

Furthermore, the results provided only modest support for the convergent validity of the CTDI-CM with the CTDI-CV. (1) Open-mindedness on the CTDI-CM is significantly correlated with Maturity on the CTDI-CV. A plausible explanation is that open-mindedness may depend on self-reflection, which shows different developmental trajectories between young adults of different cultures. However, the developmental characteristics of Open-mindedness merit further exploration. (2) Systematicity/Analyticity and Truth-seeking on the CTDI-CM were positively related to self-confidence on the CTDI-CV and negatively related to Inquisitiveness on the CTDI-CV. The latter result may reflect the different emphases of Inquisitiveness (CTDI-CV) and Truth-seeking (CTDI-CM). Inquisitiveness represents eagerness to explore the unknown and interest in mechanisms behind 


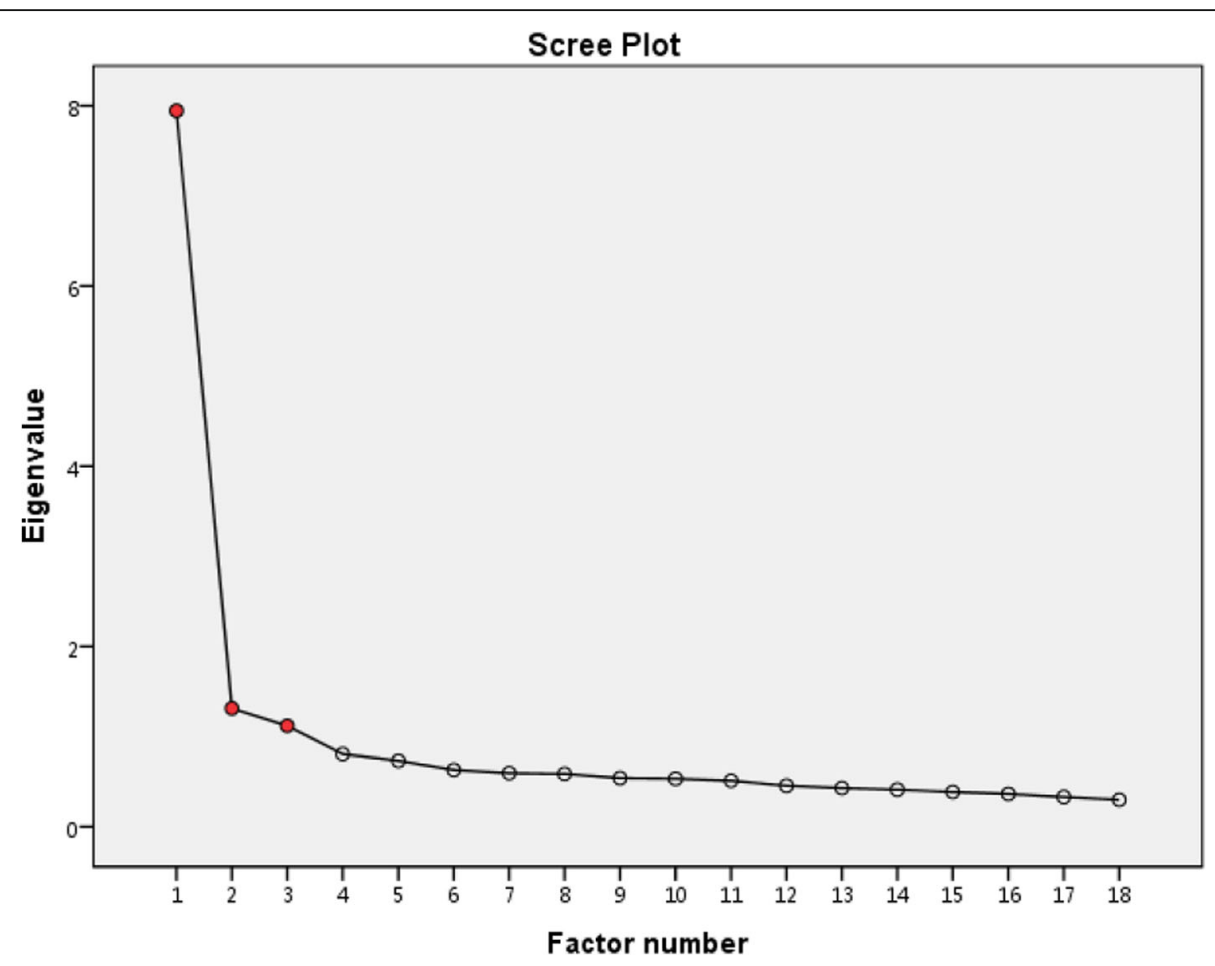

Fig. 3 Scree plot of principal axis factor analysis of CTDI-CM

phenomena, while Truth-seeking and Systematicity/Analyticity measure cognitive operations following informal and formal logical rules. Therefore, the motivation aspect of CT dispositions was less emphasized in the CTDI-CM than in the CTDI-CV, which explains the inverse relationship between the two groups of factors. Chinese philosophy and Confucius' teaching emphasize thinking as reflection in the context of relationships and identification with the interests of the whole [44], which may help to explain the negative relationship between
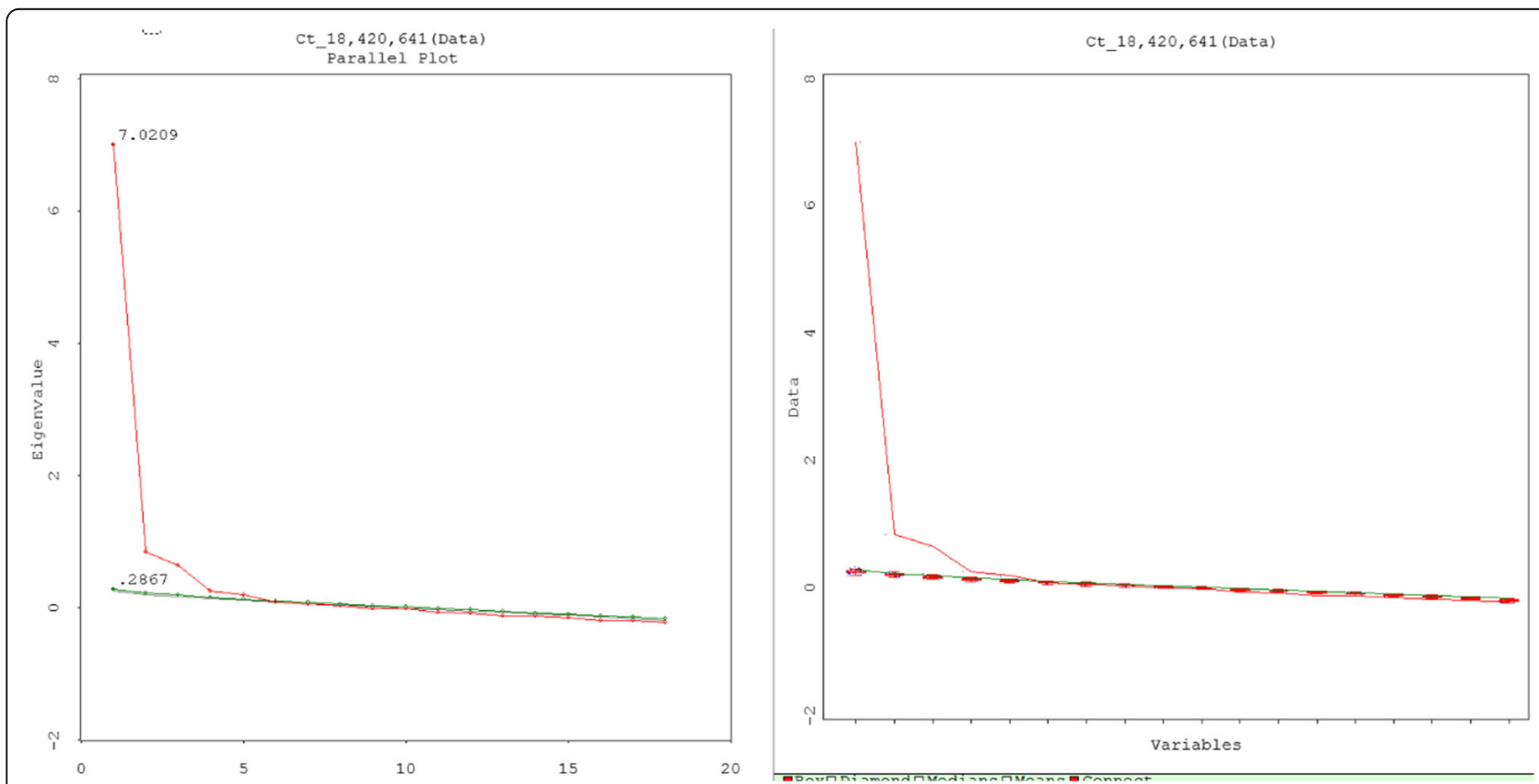

Fig. 4 Parallel analysis for factor analysis of CTDI-CM 


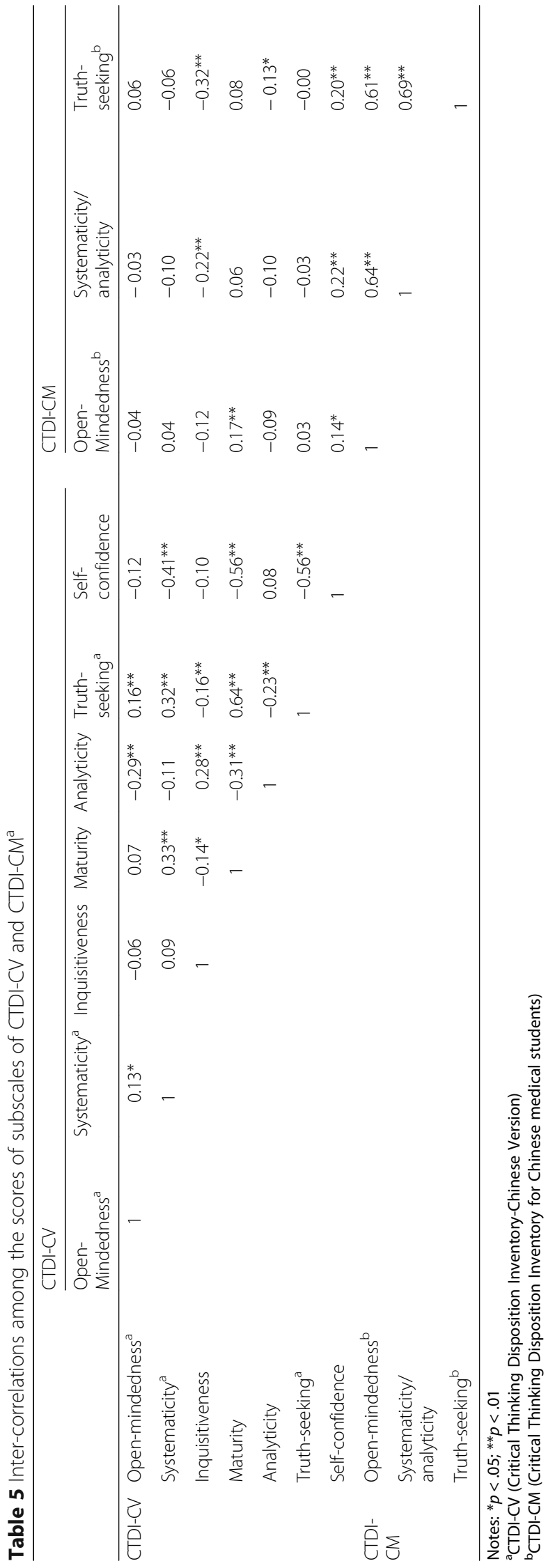


Table 6 Multiple regression coefficients of the independent variables (subscales of CTDI-CM) and the dependent variable (CDTI-CV scale)

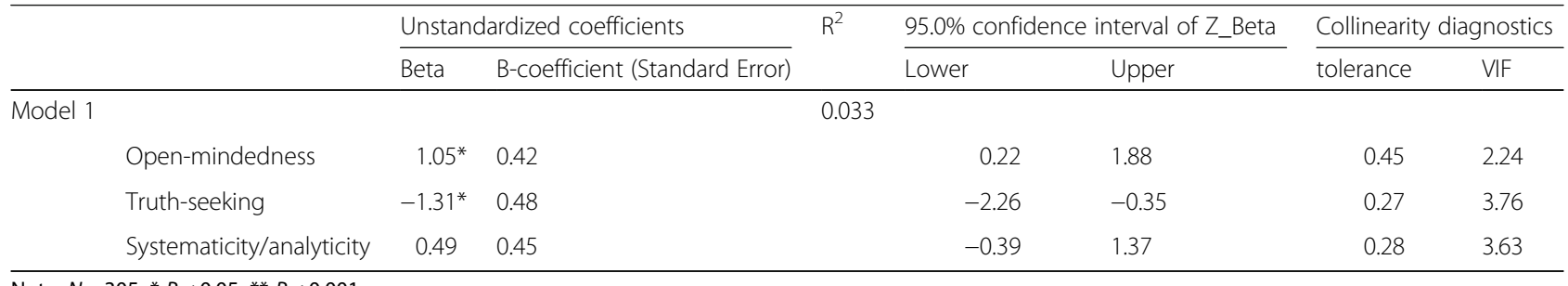

Note: $N=305 .{ }^{*} P<0.05,{ }^{* *} P<0.001$

Inquisitiveness (CTDI-CV) and Systematicity/Analyticity (CTDI-CM).

Compared with a previous study [11], the test-retest analysis of the CTDI for medical students yielded more stable results across two assessment occasions (2 weeks apart) in the current study. All correlations were statistically significant, ranging from 0.808 to 0.965 with an overall correlation of 0.881 . In addition, the results supported the internal consistency reliability of the Chinese version of the CTDI for medical students, which performed better than the two Chinese versions of the CCTDI $[10,11]$. These results confirm the current inventory as a reliable instrument for measuring the critical thinking disposition.

\section{The predictors of $\mathrm{CT}$ dispositions}

In health care, medicine and nursing may both require high critical thinking dispositions, which can lead to increased quality of care and better treatment outcomes. Our results suggest that medical students performed better on Open-mindedness and Systematicity/Analyticity than nursing students, which contrasts with previous findings. A survey conducted with the Chinese version of the CTDI (CTDI-CV) indicated that general performance for critical thinking ability in medicine and nursing was positive (overall score $>280$ ) [10]. Dispositional differences using the CCTDI among several majors [(practice disciplines, i.e., nursing, education, business) and nonpractice disciplines (i.e., English, history, psychology)] were found in a previous study, with nursing students achieving among the highest scores [45]. Another study found that the average scores for the CTDI-CV

Table 7 Comparison of mean scores of Critical Thinking Dispositions between medical and nursing students (mean \pm SD)

\begin{tabular}{lll}
\hline Factor (number of & Discipline & \\
\cline { 2 - 3 } items) & Medical students & Nursing students \\
\hline Open-mindedness & $4.07(0.58)^{\mathrm{a}}$ & $3.82(0.67)$ \\
Systematicity/analyticity & $4.05(0.55)^{\mathrm{a}}$ & $3.82(0.58)$ \\
Truth-seeking & $3.84(0.66)$ & $3.73(0.57)$ \\
\hline
\end{tabular}

Note: ${ }^{a} p<0.01$ ( 2 -tailed), independent sample t-test (medical vs. nursing students) and Analyticity in nursing were higher than those of medical students [46]. Due to the imbalance of the sample size of nursing versus medical students, further studies are needed to explore the differences in CT dispositions among majors.

\section{Limitations}

There are limitations of the current study that await further exploration. First, direct comparison of three Chinese versions of the critical thinking disposition inventory should be considered. Furthermore, due to the limitations of time and resources, we did not obtain external measures of the constructs, such as academic or professional performance, which should be addressed in the future to improve the criterion validity. Second, like most studies on critical thinking disposition, the current study was descriptive without analysing the causes of different critical thinking dispositions across cultures, such as teaching and learning strategies. Further studies may utilize active learning approaches such as problem-based learning (PBL) $[47,48]$ and intervention programmes that target motivation components, such as self-awareness and mindfulness [9], to confirm the effectiveness and validity of the CDTI-CM. Third, we mainly focused on demographic variables that may affect the critical thinking disposition. More studies are necessary to broaden the understanding of other relevant factors (e.g., motivational and cognitive variables) of the CT disposition. Finally, the self-reported disposition may be subject to demand characteristics and social desirability, which are common to CT disposition scales. Future studies require the development of more reliable tests, such as behavioural and cognitive tasks (e.g., a cognitive reflection test, which can measure Analyticity), and comparison of these different measures of critical thinking.

\section{Conclusions}

The current study developed a questionnaire (CTDI-CM) to evaluate the critical thinking dispositions of Chinese medical students. The CTDI-CM includes three factors, Open-mindedness, Systematicity/Analyticity and Truth-seeking, which measure the motivation and cognitive 
components of the CT dispositions of medical college students. The CTDI-CM was confirmed to be a reliable and valid CT measurement. Age, gender and major were significant predictors of the CT dispositions of Chinese medical college students.

\begin{abstract}
Abbreviations
AGFI: Adjusted goodness-of-fit index; CCTDI: California Critical Thinking Disposition Inventory; CFA: Confirmatory factor analysis; CFI: Comparative fit index; CR: Critical ratio; CT: Critical thinking; CTDI-CM: Critical Thinking Disposition Inventory for Chinese Medical College Students; CTDI-CV: (Critical Thinking Disposition Inventory-Chinese Version); CVI: Content validity index; EFA: Exploratory factor analysis; GFI: Goodness-of-fit index; GLM: General linear model; GMER: Global Minimum Essential Requirements; ICCs: Intra-class correlation coefficients; KMO: Kaiser-Meyer-Olkin; RMSEA: Root-mean-square error of approximation
\end{abstract}

\section{Acknowledgements}

We are deeply grateful for the comments of Dr. Mark Battersby to the manuscript. In addition, we appreciate for the helpful discussions with Dr. Dongping Gao during preparation of the manuscript.

\section{Funding}

This study was supported by a grant from the Medical Education Branch of Chinese Medical Association and the Medical Education Professional Committee of Chinese Association of Higher Education in 2010 (2010-02-33), the project of teaching reform research of Army Medical University (2014B06) and the Project of Innovation and Entrepreneurship Training for College Students (201590031003).

\section{Availability of data and materials}

The datasets within the current study are available upon request from the corresponding author.

\section{Authors' contributions}

XXW made substantial contributions to the study design and conception analysed the data and wrote the manuscript. XXS made substantial contributions to the data collection and interpretation. THH made substantial contributions to data collection and interpretation and revised the manuscript critically. $\mathrm{ROH}$ made substantial contributions to the data collection, analysis and interpretation. WNH made substantial contributions to the data collection, analysis and interpretation. LZ developed the study design and made substantial contributions to the study conception. All authors read and approved the final manuscript.

\section{Ethics approval and consent to participate}

The project and the informed consent procedures were approved by the Ethics Committee of Army Medical University. The consent procedures included the following items, which were explained to potential participants: (1) participation in the study was voluntary, and the participants were allowed to withdraw at any time during the study; (2) the purpose and methodology of the study and the expected duration of participation; (3) the questionnaires would be used only for scientific use, and the research records identifying the participants will be maintained confidentiality. Verbal consents from the participants were obtained at the time of recruitment.

\section{Consent for publication}

Not applicable.

\section{Competing interests}

The authors declare that they have no competing interests.

\section{Publisher's Note}

Springer Nature remains neutral with regard to jurisdictional claims in published maps and institutional affiliations.

\section{Author details}

'Department of Basic Psychology, School of Psychology, Army Medical University, Chongqing 400038, China. ${ }^{2}$ Department of Psychological Nursing, School of Nursing, Army Medical University, Chongqing 400038, China.

Received: 14 September 2018 Accepted: 3 May 2019

Published online: 13 June 2019

\section{References}

1. Gupta M, Upshur R. Critical thinking in clinical medicine: what is it? J Eval Clin Pract. 2012;18(5):938-44.

2. Athari ZS, Sharif SM, Nasr AR, Nematbakhsh M. Assessing critical thinking in medical sciences students in two sequential semesters: does it improve? J Educ Health Promot. 2013;2:5.

3. Papp KK, Huang GC, Lauzon CL, Delva D, Fischer M, Konopasek L, et al. Milestones of critical thinking: a developmental model for medicine and nursing. Acad Med. 2014

4. Harasym PH, Tsai T, Hemmati P. Current trends in developing medical Students' critical thinking abilities. Kaohsiung J Med Sci. 2008;24(7):341-55.

5. Shirkhani S, Fahim M. Enhancing critical thinking in foreign language learners. Procedia - Soc Behav Sci. 2011;29:111-5.

6. Aizikovitsh-Udi E, Radakovic N. Teaching probability by using Geogebra dynamic tool and Implemanting critical thinking skills. Procedia - Soc Behav Sci. 2012:46(0):4943-7.

7. Hajhosseiny M. The effect of dialogic teaching on students' critical thinking disposition. Procedia - Soc Behav Sci. 2012;69:1358-68.

8. Jenicek M, Croskerry P, Hitchcock DL. Evidence and its uses in health care and research: the role of critical thinking. Med Sci Monitor. 2011;17(1):A12-7.

9. Krupat E, Sprague JM, Wolpaw D, Haidet P, Hatem D, O'Brien B. Thinking critically about critical thinking: ability, disposition or both? Med Educ. 2011; 45(6):625-35

10. Peng $M$, Wang $G$, Chen J. Validity and reliability of the Chinese critical thinking disposition inventory. Chin J Nurs. 2004;39(9):644-7.

11. Yeh ML. Assessing the reliability and validity of the Chinese version of the California critical thinking disposition inventory. Int J Nurs Stud. 2002;39(2): 123-32.

12. Facione NC, Facione PA, Sanchez CA. Critical thinking disposition as a measure of competent clinical judgement: the development of the California critical thinking disposition inventory. J Nurs Educ. 1994;33(8): 345-50.

13. Luo Q, Yang X. Revision for CCTDI (Chinese version). Psychol Dev Educ. 2001;(3):47-51.

14. Jenkins SD. Cross-cultural perspectives on critical thinking. J Nurs Educ. 2011:50(5):268-74

15. Li X, Li X, Lü A. A comparative study on critical thinking ability of college nursing students in China. Japan and Samoa CHINESE NURSING RESEARCH. 2006;20(6B):1521-3.

16. Salsali M, Tajvidi M, Ghiyasvandian S. Critical thinking dispositions of nursing students in Asian and non-Asian countries: a literature review. Glob J Health Sci. 2013:5(6):172-8.

17. Xie Z, Cao W, Zhang W, Zhu H, Zhang W. Critical thinking dispositions and related factors among medical undergraduates. China Higher Med Educ. 2014(10):31-2

18. Tang T. Thought discrepancies - on language and culture between Chinese and westerners. Journal Hainan Normal University. 2004;17(72):93-6.

19. Wang $X$, Sun $H$, Zhang A, Sun W, Wang P, Wang Z. Potential role of metabolomics apporoaches in the area of traditional Chinese medicine: as pillars of the bridge between Chinese and Western medicine. J Pharmaceut Biomed. 2011:55(5):859-68.

20. Nisbett RE. The influence of culture: holistic versus analytic perception. Trends Cogn Sci. 2005:9(10):467-73.

21. Dwyer $C P$, Hogan MJ, Stewart I. An integrated critical thinking framework for the 21st century. Think Skills Creat. 2014;12:43-52

22. Albergaria-Almeida P. Critical thinking, questioning and creativity as components of intelligence. Procedia - Soc Behav Sci. 2011;30:357-62.

23. Peng K, Nisbett RE. Culture, dialectics, and reasoning about contradiction. Am Psychol. 1999:54(9):741.

24. Ku KYL, Ho IT. Dispositional factors predicting Chinese students' critical thinking performance. Pers Indiv Differ. 2010;48(1):54-8.

25. Spencer $C$. Critical thinking in nursing: teaching to diverse groups. Teach Learn Nurs. 2008;3(3):87-9. 
26. Aizikovitsh E, Amit M. Evaluating an infusion approach to the teaching of critical thinking skills through mathematics. Procedia - Soc Behav Sci. 2010; 2(2):3818-22.

27. Kermansaravi F, Navidian A, Kaykhaei A. Critical thinking dispositions among junior, senior and graduate nursing students in Iran. Procedia - Soc Behav Sci. 2013;83(0):574-9.

28. Shiau SJ, Chen CH. Reflection and critical thinking of humanistic care in medical education. Kaohsiung J Med Sci. 2008;24(7):367-72.

29. Wojtczak A, Schwarz MR. Global minimum essential requirements: road to competence-oriented assessment of medical education programs. Educación Médica. 2003.

30. Stern DT, Wojtczak A, Schwarz MR. Global minimum essential requirements in medical education. Med Teach. 2002;24(2):130-5.

31. Kenimer EA. The identification and description of critical thinking behaviours in the practice of clinical laboratory science, part 1: design, implementation, evaluation, and results of a national survey. J Allied Health. 2002;31(2):56-63.

32. Mosier Cl, McQuitty JV. Methods of item validation and abacs for item-test correlation and critical ratio of upper-lower difference. Psychometrika. 1940; 5(1):57-65.

33. Field A. Discovering statistics using IBM SPSS statistics. 2nd ed. London: SAGE Publication; 2013.

34. George D, Mallery P. SPSS for Windows step by step: A simple guide and reference 11.0 update. 4th ed. Boston, MA, USA: Allyn \& Bacon; 2003.

35. Kuo S, Hou W, Chang C, Liao Y, Cheng S, Chou Y, et al. Development and psychometric testing of the Chinese version of the resilience scale for southeast Asian immigrant women who divorced in Taiwan. PLoS One. 2019;14(2):e211451.

36. Cicchetti DV, Sparrow SA. Developing criteria for establishing interrater reliability of specific items: applications to assessment of adaptive behaviour. Am J Ment Defic. 1981;86(2):127-37.

37. O'Connor BP. SPSS and SAS programs for determining the number of components using parallel analysis and velicer's MAP test. Behav Res Methods Instrum Comput. 2000;32(3):396-402.

38. Ledesma RD, Valero-Mora P. Determining the number of factors to retain in EFA: an easy-to-use computer program for carrying out parallel analysis. Practical Assessment. Res Eval. 2007;12(2):1-11.

39. Maccallum RC, Austin JT. Applications of structural equation modelling in psychological research. Annu Rev Psychol. 2000;51(1):201-26.

40. Jans-Beken L, Lataster J, Leontjevas R, Jacobs N. Measuring gratitude: a comparative validation of the Dutch gratitude questionnaire (GQ6) and short gratitude, resentment, and appreciation test (SGRAT). Psychol Belg. 2015;55(1):19-31.

41. Fábián GN. Non-critical thinking: what if not thinking? Procedia - Soc Behav Sci. 2015;186:699-703.

42. Yeh ML, Chen HH. Comparison affective dispositions towards critical thinking across Chinese and American baccalaureate nursing students. J NURS RES. 2003;11(1):39-46.

43. Tiwari A, Avery A, Lai P. Critical thinking disposition of Hong Kong Chinese and Australian nursing students. J Adv Nurs. 2003:44(3):298-307.

44. Li L, Wegerif R. What does it mean to teach thinking in China? Challenging and developing notions of 'Confucian education'. Think Skills Creat. 2014; 11(0):22-32

45. Walsh CM, Hardy RC. Dispositional differences in critical thinking related to gender and academic major. J Nurs Educ. 1999;38(4):149-55.

46. Ling B, Yaqing Z, Ying C, Ping W, Li-sha L. Analysis on current status and related factors of critical thinking ability in nursing and med-ical undergraduates. Chinese J School Doctor. 2010;9B(27):1369-72.

47. Ozturk C, Muslu GK, Dicle A. A comparison of problem-based and traditional education on nursing students' critical thinking dispositions. Nurse Educ Today. 2008:28(5):627-32

48. Yu D, Zhang Y, Xu Y, Wu J, Wang C. Improvement in critical thinking dispositions of undergraduate nursing students through problem-based learning: a crossover-experimental study. J Nurs Educ. 2013;52(10):574-81.

Ready to submit your research? Choose BMC and benefit from:

- fast, convenient online submission

- thorough peer review by experienced researchers in your field

- rapid publication on acceptance

- support for research data, including large and complex data types

- gold Open Access which fosters wider collaboration and increased citations

- maximum visibility for your research: over $100 \mathrm{M}$ website views per year

At $\mathrm{BMC}$, research is always in progress.

Learn more biomedcentral.com/submissions 